\title{
Changes in plasma nephelometry after oral fat loading in children with normal and abnormal small intestinal morphology
}

\author{
M. F. ROBARDS \\ From Queen Elizabeth Hospital for Children, London
}

\begin{abstract}
Robards, M. F. (1975). Archives of Disease in Childhood, 50, 631. Changes in plasma nephelometry after oral fat loading in children with normal and abnormal small intestinal morphology. A standardized oral fat load has been given to 66 children having duodenal or jejunal biopsy, and to 10 children presumed normal. The rise in plasma light scattering intensity (LSI) measured by nephelometry between the fasting and 2-hour postload level (0-2 hour) showed good correlation with the small intestinal morphology in patients suspected of having coeliac disease. In those who had had recurrent diarrhoea and gastroenteritis, the fat load test did not predict small intestinal morphology.

Serial studies in 5 treated patients with malabsorption showed increase in the 0-to 2-hour LSI, with corresponding improvement of small intestinal morphology and clinical state.
\end{abstract}

The increase in serum or plasma particulate fat after an oral fat load has been the basis of several tests for fat malabsorption (Frazer and Stewart, 1937; Goldbloom, Blake, and Cameron 1964; Osmon, Zinn, and Wharton, 1957; Mullinger, 1968; Fosbrooke and Rudd, 1966; Penfold, 1967; Penfold and Keynes, 1971). In recent years, however, Stone and Thorp (1966) have shown nephelometry to be a far more convenient method for estimating particulate fat in serum or plasma than those used previously, and results correlate well with those of established methods (Buckley et al., 1970; Stone and Thorp, 1966; Stone et al., 1970). Nephelometry (Bentley, Eastham, and Lane, 1975) has not previously been used to quantify fat absorption. Furthermore, the results of other particulate fat tests have usually been compared with the degree of steatorrhoea as measured by estimating faecal fat but with little or no reference to small intestinal morphology.

This study was designed to determine the value of plasma nephelometry after an oral fat load as a prediction of small intestinal morphology in children.

\section{Materials and methods}

Patients. 6 groups of children were studied.

Received 9 January 1975.
Their ages and anthropometric details are shown in Table I.

Group I. Presumed normal. 10 children who had no signs or symptoms of gastrointestinal disorder. While they were being investigated for disease of other systems, a fat load was performed and blood taken simultaneously for nephelometry and other purposes. These children were presumed to have normal small intestinal morphology.

Group II. Coeliac excluded, biopsy normal. 26 children being investigated for suspected coeliac disease. They were all having a gluten-containing diet at the time of biopsy and were all shown to have normal small intestinal morphology, thus excluding coeliac disease. None of these children had had gastroenteritis or recurrent diarrhoea. They were mainly being investigated for short stature, rickets, iron deficiency anaemia, or failure to thrive.

Group III. Postgastroenteritis, biopsy normal. 9 children who had had gastroenteritis followed by recurrent diarrhoea. At the time of biopsy they were receiving normal diet and small intestinal morphology was normal.

Group IV. Postgastroenteritis, biopsy abnormal. 5 children suffering recurrent diarrhoea after gastroenteritis, all of whom had some degree of villous atrophy. These children were significantly younger than those 
of group III suffering similar symptoms who had normal gastrointestinal morphology. They were all below the 10th centile for weight and were on various diets. These 5 children have now been followed up for between 1 and 3 years and are all thriving on a normal gluten-containing diet.

Group V. Partly treated coeliac, partial villous atrophy. 5 children who were failing to thrive on gluten-containing diets and were biopsied shortly after exclusion of gluten from the diet. These children have partial villous atrophy, and follow-up from 1 to 3 years in all of them showed a good clinical response to glutenfree diet. 4 of these probably have coeliac disease and 1 has proven coeliac disease with a normal biopsy after gluten exclusion and villous atrophy during subsequent gluten challenge.

Group VI. Probable coeliac disease, subtotal villous atrophy. 13 children with probable coeliac disease. These had subtotal villous atrophy while on a glutencontaining diet and all had good clinical response to gluten exclusion over a 1- to 3-year follow-up period. The youngest of this group (Case 1, Table II) has proven coeliac disease with a normal biopsy after gluten exclusion and villous atrophy after rechallenge with gluten. Apart from a 6-month-old child in this group with a sib having coeliac disease, the other children were all over 10 months of age.

Fat load. Patients were fasted from 10.00 p.m. the night before the test and given clear fluid only if required. At $9.00-9.30$ a.m. $2 \mathrm{ml}$ of blood were taken by venepuncture into lithium heparin. A feed containing $1 \mathrm{~g}$ fat/kg body weight was then given. For infants this was usually contained in a normal Full
Cream Cow and Gate (FCCG) prepared feed (fat $3.1 \mathrm{~g} / 100 \mathrm{ml})$. For older children the load was given as FCCG supplemented with double cream (fat 48$50 \mathrm{~g} / 100 \mathrm{ml}$ ), with gluten-free cereal, fruit, and sugar to taste. Further blood samples were taken 2 and 3 hours after completion of the breakfast. Normal feeding was then resumed.

Nephelometry. Estimations of light scattering intensity (LSI) were performed on the same day as the load. Blood samples were centrifuged and the plasma separated, including the surface layer of lipoprotein material if present. The plasma was then mixed (recentrifugation after a trial period was found unnecessary with careful separation) and diluted 1 in 10 with normal saline. Lipaemic plasma samples sometimes required further dilution to bring the LSI within the range of the nephelometer* (Thorp, Horsfall, and Stone 1967). With the diluted plasma (minimum volume $2.5 \mathrm{ml}$ ) in an optically adjusted glass tube, the LSI was read in the nephelometer against the supplied standard. The diluted fasting plasma was then passed through a cellulose nitrate microfilter, pore size $0.05 \mu \mathrm{m}$ and the LSI reread after allowing bubbles to settle for 10 minutes. If the LSI of the fasting sample exceeded 60 units, and this was attributable mostly to chylomicrons (by finding that the LSI fell dramatically after the filtration procedure), then the patient was considered not properly fasted and the result ignored. No attempt was made to estimate triglyceride levels from the nephelometric results, and all results are given as LSI units.

*Micronephelometer, Scientific Furnishings Ltd., Industrial Estate, Chichester. 
udied

\begin{tabular}{|c|c|c|c|c|}
\hline \multirow{2}{*}{$\begin{array}{l}1 \text { or below } \\
\text { nd \%) } \\
\text { Weight }\end{array}$} & \multirow{2}{*}{$\begin{array}{l}\text { Biopsy } \\
\text { findings }\end{array}$} & \multicolumn{3}{|c|}{$\begin{array}{l}\text { Light scattering intensity } \\
\text { (mean and range) }\end{array}$} \\
\hline & & Fasting & $2 \mathrm{~h}$ & $0-2 \mathrm{~h}$ \\
\hline $\begin{array}{c}7 \\
(70)\end{array}$ & Not done & $\begin{array}{l}25 \\
(16-39)\end{array}$ & $\begin{array}{c}216 \\
(110-353)\end{array}$ & $\begin{array}{c}191 \\
(92-316)\end{array}$ \\
\hline $\begin{array}{c}17 \\
(65)\end{array}$ & Normal & $\begin{array}{l}23 \\
(12-50)\end{array}$ & $\begin{array}{c}190 \\
(94-400)\end{array}$ & $\begin{array}{c}167 \\
(74-372)\end{array}$ \\
\hline $\begin{array}{c}3 \\
(33)\end{array}$ & Normal & $\stackrel{23}{(13-44)}$ & $\begin{array}{c}103 \\
(53-177)\end{array}$ & $\begin{array}{c}80 \\
(39-158)\end{array}$ \\
\hline $\begin{array}{c}5 \\
(100)\end{array}$ & $\begin{array}{l}\text { Partial or } \\
\text { subtotal } \\
\text { villous } \\
\text { atrophy }\end{array}$ & $\stackrel{22}{(17-31)}$ & $\begin{array}{c}89 \\
(38-190)\end{array}$ & $\begin{array}{c}76 \\
(7-170)\end{array}$ \\
\hline $\begin{array}{c}3 \\
(60)\end{array}$ & $\begin{array}{l}\text { Partial villous } \\
\text { atrophy }\end{array}$ & $\begin{array}{c}20 \\
(13-35)\end{array}$ & $\begin{array}{c}55 \\
(26-71)\end{array}$ & $\begin{array}{c}35 \\
(13-51)\end{array}$ \\
\hline$\stackrel{9}{9}$ & $\begin{array}{l}\text { Subtotal } \\
\text { villous } \\
\text { atrophy }\end{array}$ & $\begin{array}{c}28 \\
(15-51)\end{array}$ & $\begin{array}{c}62 \\
(23-139)\end{array}$ & $\begin{array}{c}34 \\
(3-106)\end{array}$ \\
\hline
\end{tabular}

Small intestinal biopsy. Small intestinal biopsy was performed perorally using a Crosby or Watson capsule. The capsule was manipulated into the fourth part of the duodenum or proximal jejunum under fluoroscopic screening or else manipulated 'blind' and the position confirmed by a single $x$-ray film. Immediately after obtaining the biopsy it was inspected under the dissecting microscope and then fixed for histological study. Biopsy results were interpreted as normal, partial villous atrophy, or subtotal villous atrophy.

\section{Results}

Table I shows the LSI fasting, at 2 hours, and the rise from fasting to 2 hours in the 6 groups of children. Fig. 1 shows the 0 - to 2-hour rise of LSI in the 6 groups and the mean of each group.

The main difference between the children with normal and abnormal small intestinal morphology was found to be the 0 - to 2-hour LSI rise. The 3-hour LSI level was found useful only in cases where the 0- to 2-hour rise was borderline and in practice might indicate delayed gastric emptying if higher than the 2-hour level.

The unbiopsied children with no signs or symptoms of gastrointestinal disease (group I) had an LSI rise similar in range and mean to the children with proved normal gastrointestinal morphology (group II). There were 4 patients in group II who had an LSI rise of 340 or more units, all of these had been management problems and were underfed; they showed rapid weight gain with normal feeding.
Of the children with recurrent diarrhoea after gastroenteritis, 4 who had a normal biopsy showed an LSI rise below the normal range, and 2 who had an abnormal biopsy showed a normal rise in LSI. In these 2 groups of patients the LSI rise was not a useful indicator of intestinal morphology.

Patients of group V all showed an LSI rise below the normal range. Only 1 patient of group VI (Case 2, Table II) showed a normal rise in LSI.

Serial results during treatment. 5 patients were studied serially and details are shown in Table II. The results of the fat loading tests are shown in Fig. 2. Case 1 is the youngest child of the probable coeliac group who was later proved to have coeliac disease. Before gluten exclusion the LSI rise was below the normal range and 3 weeks after gluten exclusion it was well within the normal range. Subsequent biopsy showed normal small intestinal morphology. Case 2 was the only child in the probable coeliac disease group with an initially normal rise in LSI. His fat load was repeated one week after the first load, coinciding with one week of gluten exclusion. The second LSI rise was 272 units, representing a marked increase. Subsequent small intestinal biopsy while on a gluten-free diet was normal; subtotal villous atrophy later developed with gluten challenge. Case 3 was a 9-year-old girl with tropical sprue, characterized by gross malabsorption, megaloblastic anaemia, and folate deficiency with a small 


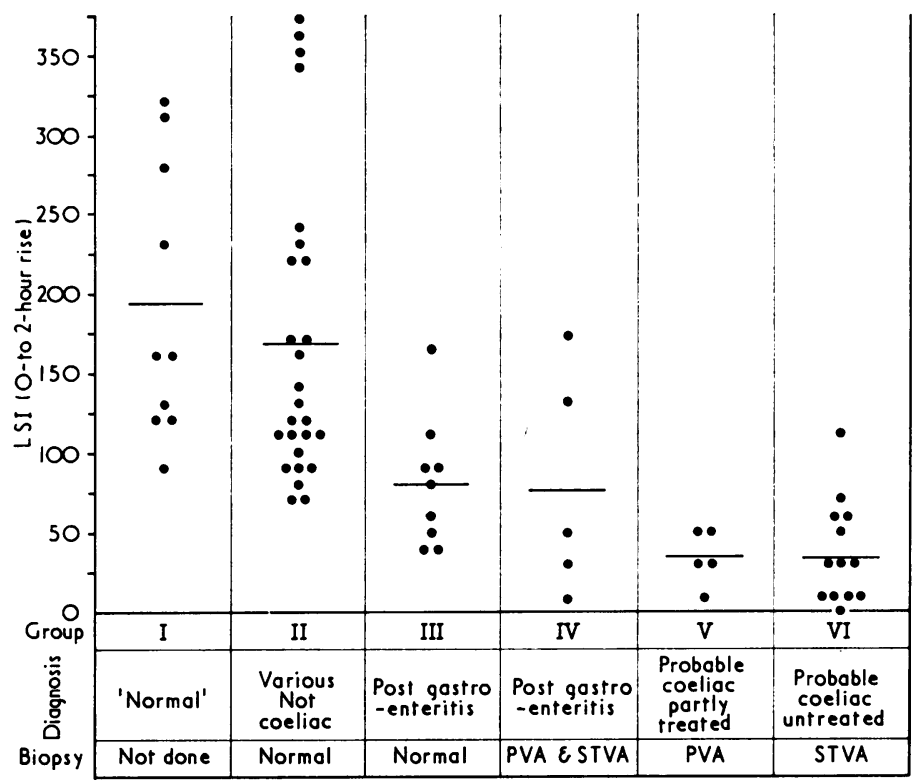

FIG. 1.-0- to 2-hour rise in light scattering intensity (LSI) in groups I-VI. PVA, partial villous atrophy; STVA, subtotal villous atrophy.

intestinal biopsy showing subtotal villous atrophy while on a normal diet. Her LSI rise at this time was insignificant. After 3 weeks of therapeutic oral folate therapy continuing with a normal diet her LSI rise was well within the normal range, associated with clinical and haematological recovery. Against medical advice, her folate therapy was discontinued and a subsequent biopsy showed partial villous atrophy. The folate supplements were started again and a third biopsy was normal.

Cases 4 and 5 were similar. They were both under 6 months of age and presented with severe marasmus, gluten intolerance which proved to be transient, absent pancreatic amylase, and gross malabsorption. They will be described more fully elsewhere. The first child had subtotal villous

TABLE II

Patients studied serially

\begin{tabular}{|c|c|c|c|c|c|c|}
\hline \multirow{2}{*}{ Case no. } & \multirow{2}{*}{$\begin{array}{l}\text { Age at first } \\
\text { load (yr) }\end{array}$} & \multirow{2}{*}{ Diagnosis } & \multirow{2}{*}{ Therapy } & \multirow{2}{*}{$\begin{array}{c}\text { Time between fat } \\
\text { loads }(w)\end{array}$} & \multicolumn{2}{|c|}{ Biopsy } \\
\hline & & & & & Before therapy & After therapy \\
\hline 1 & $0 \cdot 3$ & Coeliac & Gluten exclusion & 3 & $\begin{array}{l}\text { Subtotal } \\
\text { villous atrophy }\end{array}$ & Normal \\
\hline 2 & $2 \cdot 3$ & Coeliac & Gluten exclusion & 1 & $\begin{array}{l}\text { Subtotal } \\
\text { villous atrophy }\end{array}$ & Normal \\
\hline 3 & $9 \cdot 5$ & $\begin{array}{c}\text { Tropical } \\
\text { sprue }\end{array}$ & $\begin{array}{l}\text { Normal diet and } \\
\text { oral folate }\end{array}$ & 3 & $\begin{array}{l}\text { Subtotal } \\
\text { villous atrophy }\end{array}$ & $\begin{array}{l}\text { Partial villous } \\
\text { atrophy, then } \\
\text { normal }\end{array}$ \\
\hline 4 & 0.5 & $\begin{array}{c}\text { Marasmus, } \\
\text { transient } \\
\text { gluten } \\
\text { intoler- } \\
\text { ance }\end{array}$ & $\begin{array}{l}\text { Gluten, starch, } \\
\text { disaccharide } \\
\text { exclusion }\end{array}$ & 8,4 & $\begin{array}{l}\text { Subtotal } \\
\text { villous atrophy }\end{array}$ & $\begin{array}{l}\text { Partial villous } \\
\text { atrophy, then } \\
\text { normal } \times 2\end{array}$ \\
\hline 5 & $0 \cdot 3$ & $\begin{array}{l}\text { Marasmus, } \\
\text { transient } \\
\text { gluten } \\
\text { intoler- } \\
\text { ance }\end{array}$ & $\begin{array}{l}\text { Gluten, starch, } \\
\text { disaccharide } \\
\text { exclusion }\end{array}$ & 64 & $\begin{array}{l}\text { Subtotal } \\
\text { villous atrophy }\end{array}$ & Normal $\times 2$ \\
\hline
\end{tabular}




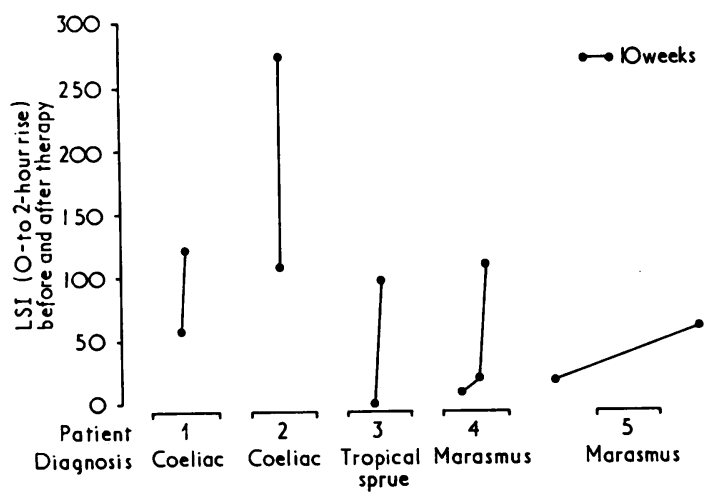

FIG. 2.-0- to 2-hour rise in light scattering intensity $(L S I)$ before and after treatment in 5 patients studied serially.

atrophy initially and 2 fat loads 8 weeks apart showed an LSI rise below normal, which improved over the next month, reaching normal levels. A further biopsy was performed which showed partial villous atrophy and then a normal biopsy was obtained on a gluten-free diet. A fourth biopsy was normal after a 3-month gluten challenge. This child is now thriving on a normal diet. The second of these 2 patients had an LSI rise well below the normal level initially, at which time small intestinal biopsy showed subtotal villous atrophy. 64 weeks later his LSI rise was improved but still not within the normal range. $\mathrm{He}$ subsequently had a normal biopsy before introduction of gluten and a normal biopsy after a 3-month gluten challenge and is now thriving on a normal diet.

\section{Discussion}

The oral fat load described has the advantage that it is a single physiological challenge and produced repeatable results in adults and in the 4 children in whom the test has been repeated under stable conditions.

In general the LSI rise of the children with abnormal small intestinal morphology was below that of the children with normal morphology, but there was some overlap occurring mainly in the children with recurrent diarrhoea following gastroenteritis. After excluding these children, the overlap between children with normal and abnormal small intestinal morphology is represented by only 1 case.

The mucosal abnormality in children dying of gastroenteritis is patchy (Walker-Smith, 1972), so that biopsy findings in recurrent gastroenteritis may not represent the overall small intestinal mucosa. In adults dying with coeliac disease there may be local variation in the degree of mucosal abnormality proximally (Thompson, 1974) where the severity of the enteropathy is greatest (MacDonald et al., 1964). Nevertheless, the mucosal changes in coeliac disease are probably more uniform than in postgastroenteritis malabsorption; this could explain the good correlation of LSI rise with biopsy findings in suspected coeliac cases and the poor correlation in postgastroenteritis malabsorption. It is likely that overall enterocyte function which is probably reflected by the LSI rise is more closely related to biopsy findings in the suspected coeliac cases than the postgastroenteritis patients. Variation in gastric emptying rate may also affect the reliability of the LSI rise in the postgastroenteritis children.

The serial study, limited though it is, does show the correlation between improved LSI rise and improved clinical state and morphology of biopsy material. The first 2 children showed a rapid improvement of their LSI rise. One was the very young coeliac case and the other the only child of the probable coeliac group to have a pretreatment LSI within the normal range. He showed a dramatic improvement in his LSI rise over a period of only 1 week of gluten exclusion, and coeliac disease was later proved. The third very fast responder was the girl with tropical sprue who had the lowest pretreatment LSI rise of any patient. She was at this time extremely emaciated. Her clinical improvement over the 3 weeks of oral folate therapy before the second load test was dramatic. The 2 children with marasmus and transient gluten intolerance were similar in their clinical presentation and in their very slow response to dietary modification which correlates well with their slow improvement of LSI rise.

\section{Conclusion}

This test could be a suitable procedure for screening children with suspected malabsorption.

If the test shows a low LSI rise then biopsy is obviously indicated. Therefore it is probably not justifiable to subject children of short stature with no other evidence of malabsorption to either small intestinal biopsy or 5-day faecal fat collections. However, the overlap of results in the children with diarrhoea following gastroenteritis means that results of fat loading tests on such children should be interpreted with caution and this limits the usefulness of the test.

Many clinicians are now repeating small intestinal biopsies in suspected coeliac patients after gluten exclusion and after further gluten challenge. 
Young and Pringle (1971) have found that the time elapsing before mucosal changes develop is variable, and the decision when to re-biopsy is generally made on clinical grounds. Perhaps the fat load and nephelometry will give a better indication than the clinical findings alone as to when to repeat the biopsy. This test could also be used in other situations where fat digestion or absorption is in question and possibly to monitor the effect of preparations designed to improve fat digestion and absoprtion.

I thank all the clinicians who gave me access to their patients, with particular appreciation to Drs. B. Wharton, J. A. Walker-Smith, and Mary Rossiter, and Sister Lesley Robertson for their considerable practical help and advice.

\section{REFERENCES}

Bentley, S. J., Eastham, R. D., and Lane, R. F. (1975). Oral butter fat test meal with serum nephelometry in suspected fat malabsorption. Fournal of Clinical Pathology, 28, 80.

Buckley, J. A., Deegan, T., Muirhead. R. A., and Williams, M. J. (1970). The application of nephelometry in the estimation of serum and plasma glyceride levels. Clinica Chimica Acta, 28, 133.

Fosbrooke, A. S., and Rudd, B. T. (1966). The determination of particulate fat in serum and its use in clinical studies. Clinica Chimica Acta, 13, 251.

Frazer, A. C., and Stewart, H. C. (1937). Ultramicroscopic particles in normal human blood. Fournal of Physiology, 90, 18.
Goldbloom, R. B., Blake, R. M., and Cameron, D. (1964). Assessment of three methods for measuring intestinal fat absorption in infants and children. Pediatrics, 34, 814.

MacDonald, W. C., Brandborg, L. L., Flick, A. L., Trier, J. S., and Rubin, C. E. (1964). Studies of celiac sprue. IV. The response of the whole length of the small bowel to a glutenfree diet. Gastroenterology, 47, 573.

Mullinger, M. (1968). The effect of exogenous pancreatic enzymes on fat absorption. Pediatrics, 42, 523.

Osmon, K. L., Zinn, W. J., and Wharton, G. K. (1957). Simplified test of fat absorption. Fournal of the American Medical Association, 164, 633.

Penfold, W. A. F. (1967). Serum lipid levels following a fatty meal as a test of steatorrhoea. Proceedings of the Association of Clinical Biochemists, 4, 205.

Penfold, W. A. F., and Keynes, W. M. (1971). Use of standard fatty meal as a test for fat absorption. Annals of Surgery, 173, 157.

Stone, M. C., and Thorp, J. M. (1966). A new technique for the investigation of the low-density lipoproteins in health and disease. Clinica Chimica Acta, 14, 812.

Stone, M. C., Thorp, J. M., Mills, G. L., and Dick, T. B. S. (1970). Comparison of membrane filtration and nephelometry with analytical ultracentrifugation, for the quantitative analysis of low density lipoprotein fractions. Clinica Chimica Acta, 30, 809.

Thompson, H. (1974). The small intestine at autopsy. Clinics in Gastroenterology, 3, 171 .

Thorp, J. M., Horsfall, G. B., and Stone, M. C. (1967). A new red-sensitive micronephelometer. Medical and Biological Engineering, 5, 51.

Walker-Smith, J. A. (1972). Uniformity of dissecting microscope appearances in proximal small intestine. Gut, 13, 17.

Young, W. F., and Pringle, E. M. (1971). 110 children with coeliac disease, 1950-1969. Archives of Disease in Childhood, 46, 421.

Correspondence to Dr. M. F. Robards, Department of Child Health, Alder Hey Children's Hospital, Eaton Road, Liverpool L12 2AP. 